\title{
Actin expression in germinating seeds of Phaseolus vulgaris $\mathrm{L}$.
}

\author{
Marco A. Villanueva, Francisco Campos, Claudia Díaz, José M. Colmenero-Flores, Edgar Dantán, \\ Federico Sánchez, Alejandra A. Covarrubias
}

Departamento de Biología Molecular de Plantas, Instituto de Biotecnología, U.N.A.M., Apartado Postal 510-3, Cuernavaca, Morelos 62250, México

\begin{abstract}
Actin was present at very low levels in the seeds of common bean (Phaseolus vulgaris L.) compared with those from other species, and was observed mostly in the embryo. A time-course of actin expression in germinating bean seeds revealed an induced expression of both the mRNA and protein. Initially, the actin mRNA in seeds was barely detectable by northern blot analysis. However, there was a substantial increase in the expression of the actin mRNA at 24,48 and $72 \mathrm{~h}$ after imbibition, compared with an internal control consisting of a late-embryogenesis-abundant (LEA) type IV gene from $P$. vulgaris. An increase in the amount of actin in total seed extracts that parallelled that of the mRNA was detected by western blotting starting at $24 \mathrm{~h}$ after imbibition. This increase was more apparent when the embryo alone was analyzed. Two-dimensional western blots initially revealed three actin isoforms with isoelectric points (pIs) of approximately 5.6, 5.7 and 5.8, the amounts of which increased within a $48-\mathrm{h}$ period, when a new minor isoform of $\mathrm{pI}$ approximately 5.5 appeared; however, after $72 \mathrm{~h}$, the pI-5.8 isoform had almost disappeared and the pI-5.5 isoform had disappeared completely, indicating that these two minor isoforms are expressed transiently. These results indicate that actin is at very low levels in the dry seed but undergoes an increased and differential expression during imbibition, an event probably required to carry out all the necessary functions for germination.
\end{abstract}

Key words: Actin - Cytoskeleton - Gene expression (actin) - Germination - Imbibition - Phaseolus (seed actin)

\section{Introduction}

The cytoskeleton is a fundamental organelle that is involved in most essential cellular functions of eukaryotes. One of its components, actin is a ubiquitous protein that is highly regulated at various levels, including transcriptionally (Lloyd and Gunning 1993) and post-translationally (Aktories and Wegner 1992; Howard et al. 1993; Jungbluth et al. 1995). In addition, actin can self-assemble into microfilaments, and the equilibrium between polymeric and monomeric actin is also under tight cellular control by $\mathrm{pH}$, salts, and a subset of proteins that can interact with both the polymer and the monomer (Pollard and Cooper 1986; Sheterline and Sparrow 1994). All these control points are necessary since small variations in the actin monomer/polymer equilibrium can dramatically alter cell shape and function. For example, the capability of actin to polymerize can be affected by specific phosphorylation at tyrosine residues in Dictyostelium discoideum cells as a response to stress (Jungbluth et al. 1995). Consequently, this increased actin phosphorylation causes pseudopodium loss, rounding-up and reduced adhesion of $D$. discoideum cells to the substratum (Howard et al. 1993). Similarly, over-expression of an actin-binding protein such as profilin, which is presumed to induce actin depolymerization, produces slow growth, swelling and lysis of Saccharomyces cerevisiae cells, as well as an altered actin and chitin distribution compared with the wild type (Haarer et al. 1990).

While most of the data on cytoskeletal function and regulation have been obtained from studies on eukaryotes from the animal kingdom, the cytoskeleton in plant cells has also been reported to contain the main primary protein components such as actin (Vahey and Scordilis 1980; McLean et al. 1990b; Villanueva et al. 1990; Liu and Yen 1992), tubulin (Lloyd et al. 1979; Yadav and Filner 1983) and intermediate filament-like proteins (Beven et al. 1991). Among these proteins, tubulin (Yadav and Filner 1983) and actin (Andersland et al. 1992; Liu and Yen 1992; Ren et al. 1997) have been shown to self-associate, in vitro, into microtubules and 
microfilaments, respectively. Although there is a notable lack of information on the particular roles and regulation of actin in plants, there is increasing substantial evidence on the involvement of actin in many plant cellular functions. Plant actin has been observed to be an important component that works in concert with tubulin during cell division (Schmit and Lambert 1990), and the disruption of the actin network leads to a number of effects including cessation of cytoplasmic streaming, cell division, organelle movement and tip growth (McCurdy and Williamson 1991). In addition, microinjection of the actin-binding protein profilin into Tradescantia stamen hair cells disrupts microfilament organization and the cells stop cytoplasmic streaming (Staiger et al. 1994). Thus, actin is a fundamental protein in the plant kingdom as well.

Due to the variety of roles of actin in many different plant cellular functions, it is also expected that plant actin is tightly regulated wherever cytoskeletal function occurs. For example, it has been reported that actin displayed a differential expression of isoforms during nodule ontogeny in P. vulgaris (Pérez et al. 1994). This differential expression of isoforms might be induced as early in nodule ontogeny as the initial infection steps, during the rearrangement of the actin network of $P$. vulgaris root hair cells that is induced by Nod factors derived from Rhizobium etli (Cárdenas et al. 1998). In soybean, actin was reported to consist of highly divergent isovariants with possible roles in the differential regulation necessary for the plasticity of cytoskeletal function (McLean et al. 1990b). Furthermore, antibodies generated against the specific $\lambda-, \kappa$-, and $\mu$-actin isoforms, showed a preferential distribution of the $\lambda$ isoform in protoderm from apical and lateral roots and root primordia, suggesting a specificity of function for certain isovariants (McLean et al. 1990a). While germination is an intensive cell division and elongation developmental process, there are no studies on the expression and possible regulation of actin. In our laboratory, we are interested in the study of cytoskeletal components during germination and thus we analyzed the expression of actin from the dry seed of Phaseolus vulgaris through different times after seed imbibition. We observed, to our surprise, that actin is greatly diminished in the seed but its expression increases dramatically after $24 \mathrm{~h}$ both at the protein and mRNA levels. We show that the increase in the protein is due to an increase in two major protein isoforms, rather than to a shift in the isoforms themselves. These studies also indicate that the expression of actin is not as constitutive as previously thought in all eukaryotic organisms.

\section{Materials and methods}

Plant material. Seeds from Phaseolus vulgaris L. were used at all times and were obtained from the local supermarket. Seeds were surface-sterilized in $10 \%(\mathrm{v} / \mathrm{v})$ commercial bleach, rinsed in running tap water, sown on water-saturated towels and germinated in the dark at $27 \pm 1{ }^{\circ} \mathrm{C}$ and $100 \%$ relative humidity. Whole seedlings and embryo axes were harvested at different times as indicated and stored at $-70^{\circ} \mathrm{C}$ until used.
Antibodies and chemicals. Anti-(calf thymus actin) polyclonal antibodies were a kind gift from Dr. John L. Wang, Michigan State University (East Lansing, USA) and have been shown to cross-react with plant actin (Villanueva et al. 1990). Monoclonal anti-actin antibody N350 was purchased from Amersham (Arlington Heights, Ill., USA) and has also been shown to cross-react with plant actin (McLean et al. 1990b). Alkaline-phosphatase-conjugated anti-rabbit antibodies and substrates were from BoehringerMannheim (Indianapolis, Ind., USA). Ampholytes were purchased from Sigma (St. Louis, Mo., USA). All other chemicals were reagent grade.

Preparation of material for protein and RNA extracts. The surfacesterile seeds and embryo axes were used to prepare a powder by grinding them in liquid nitrogen with a mortar and pestle. The frozen powders were kept at $-80{ }^{\circ} \mathrm{C}$ until further analysis. Alternatively, a flour was also prepared by grinding the dry clean seeds or the cotyledons and embryo axes separated from them in a coffee mill.

Extraction of RNA northern blot analysis and reverse transcriptasepolymerase chain reaction ( $R T-P C R)$. Total RNA was prepared from the frozen powdered material by the hot-phenol method, following the procedure of de Vries et al. (1991). A 5- $\mu$ g sample of total RNA was electrophoresed on a $1 \%$ agarose gel in the presence of $2.2 \mathrm{M}$ formaldehyde and transferred onto nylon membranes (Sambrook et al. 1989). Blots were hybridized with P. vulgaris lateembryogenesis-abundant (LEA) class-IV (lea4-25) cDNA (Colmenero-Flores et al. 1997) and actin cDNA from leaves (PLACT-6; unpublished). Hybridization and washes were done at high stringency (Church and Gilbert 1984) and subjected to autoradiography. The RNA load was standardized by visualizing the ribosomal RNA in the gels after ethidium bromide staining. For RT-PCR, we used actin universal oligonucleotides from the carboxy terminus which is highly conserved (Sheterline and Sparrow 1994). The $5^{\prime}$ oligonucleotide encoding an adaptor sequence and a $5^{\prime}$ region (5' GGAATTCCAGTGTCTGGATTGGTGG $3^{\prime}$ ), and the $3^{\prime}$ oligonucleotide (5' GAAGCATTTCCTGTGAACTATTGATGGCCCAG $3^{\prime}$ ) were incubated in the presence of total cDNA synthesized by reverse transcriptase from total RNA extracted from different parts of the plant. The reaction was carried out using the Superscript II kit according to the instructions of the manufacturer (Gibco BRL, Gaithersburg, Md., USA) from 0 to 25 cycles, and the amplified cDNA was analyzed on $2 \%$ agarose gels. In some cases, the amplified DNA bands were quantified by densitometry by the same method used for protein bands (see below).

Sodium dodecyl sulfate-polyacrylamide gel electrophoresis (SDS$P A G E)$, two-dimensional SDS-PAGE (2-D PAGE) and immunoblotting. For whole-seed flour, the powdered material was suspended in $1 \%$ SDS and boiled immediately for $8 \mathrm{~min}$. Alternatively, the same material was suspended in Laemmli's sample buffer and processed the same way. The supernatants were recovered by centrifugation at $14,000 \mathrm{~g}$ and analyzed by SDSPAGE according to Laemmli (1970). Similarly, $0.1 \mathrm{~g}$ of frozen powdered embryos was resuspended in Laemmli's sample buffer and boiled immediately for $8 \mathrm{~min}$. For analysis by 2-D PAGE, the embryo extracts in Laemmli' s sample buffer were diluted at a 1:1 ratio in O'Farrell's (O'Farrell 1975) lysis buffer (9.5 M urea, 5\% $\beta$-mercaptoethanol, $2 \%$ nonidet $\mathrm{P}-40,1.6 \%$ ampholytes $\mathrm{pH} 5-7$, and $0.4 \%$ ampholytes pH 3.5-10) (Sinclair and Rickwood 1981). The samples were then analyzed by isoelectric focusing in the first dimension and SDS-PAGE in the second dimension according to O'Farrell (1975). For immunoblotting, the gels were electrotransferred to nitrocellulose at $400 \mathrm{~mA}$ overnight (Towbin et al. 1979) and blocked with $3 \%$ bovine serum albumin in phosphate-buffered saline (PBS; $10 \mathrm{mM}$ Na-phosphate; $150 \mathrm{mM} \mathrm{NaCl}, \mathrm{pH}$ 7.4) for $1 \mathrm{~h}$ at $50{ }^{\circ} \mathrm{C}$. The membranes were then incubated overnight at $4{ }^{\circ} \mathrm{C}$ in either a $1 / 1000$ dilution of monoclonal anti-actin antibodies, or a $1 /$ 2000 dilution of an anti-(calf thymus actin) polyclonal antibody in 
$0.05 \%$ Triton $\mathrm{X}-100$ in PBS (PBST). After three washes of $15 \mathrm{~min}$ in PBST, the membranes were incubated with a $1 / 5000$ dilution of the appropriate peroxidose- or alkaline-phosphatase-conjugated secondary antibodies for $1 \mathrm{~h}$ at $25^{\circ} \mathrm{C}$. The membranes were then washed three times for 15 min with PBST, rinsed briefly in PBS and the proteins were visualized by chemiluminescence or by incubating in a solution of nitro-blue tetrazolium and bromo-chloro indolyl phosphate according to the manufacturer (Boehringer-Mannheim).

Protein quantification and densitometry. The uniformity of protein loading in the gels was normalized by previously running the various extracts and staining with Coomassie blue. An approximation of the amount of protein loaded was determined according to Bradford (1976) using bovine serum albumin as a standard.

For densitometric scans, the images of the western blots or photographic films were captured by an Apple Color One Scanner using Adobe Photoshop software and the bands quantified according to their pixel value using NIH-Image software.

\section{Results}

Actin is present at low levels in P. vulgaris seeds and predominantly in the embryo. The presence of actin was detected by western blotting using an antibody to calf thymus actin that is known to cross-react with plant actin (Villanueva et al. 1990). When $40 \mu \mathrm{g}$ of protein from several extracts from different dry seeds was analyzed, even with a 2-fold higher protein load for $P$. vulgaris extracts, the actin could not be detected (Fig. 1B, lane 1), whereas the $42-\mathrm{kDa}$ band was readily detected in maize and oat seed extracts (Fig. 1B, lanes 2 and 3, respectively). Possible actin degradation products were also detected in a rice extract (Fig. 1B, lane 4). The facts that: (i) the amount of protein loaded was equivalent in lanes 2-4 (Fig. 1A); (ii) lane 1 where actin was not observed was actually about 2 -fold overloaded with respect to the lanes where actin was detected (Fig. 1A); and (iii) we were unable to detect proteolytic activity using gelatin as substrate in seed extracts (not shown), indicated that actin in $P$. vulgaris seeds is present at very low levels and that this finding was not due to a differential extraction caused by omitting the $\beta$-mercaptoethanol, Tris and glycerol from the extraction buffer. In fact, an identical reaction was observed in lanes loaded with the same amount of protein extracted with either $1 \%$ SDS alone (Fig. 2A, lane 2) or Laemmli's sample buffer (Fig. 2A, lane 3). In addition, the only way to observe the actin band in the $P$. vulgaris extracts was by overdeveloping the blot (Fig. 2A, lanes 2, 3; Fig. 3), but this caused a high background in the rest of the membrane (Fig. 3). A more detailed analysis of the different parts of the seed by western blotting using equal amounts of protein in each lane and after overdeveloping the blot, revealed that actin in $P$. vulgaris seeds is present mostly in the embryo (Fig. 2B, lane 2) since the equivalent extract from total seed (Fig. 2B, lane 1) or cotyledon (Fig. 2B, lane 3 ) showed a very faint reaction. These data indicated that most of the actin during germination arises from the embryo, and prompted us to check the time-course of its expression in both total seeds and embryo axes.

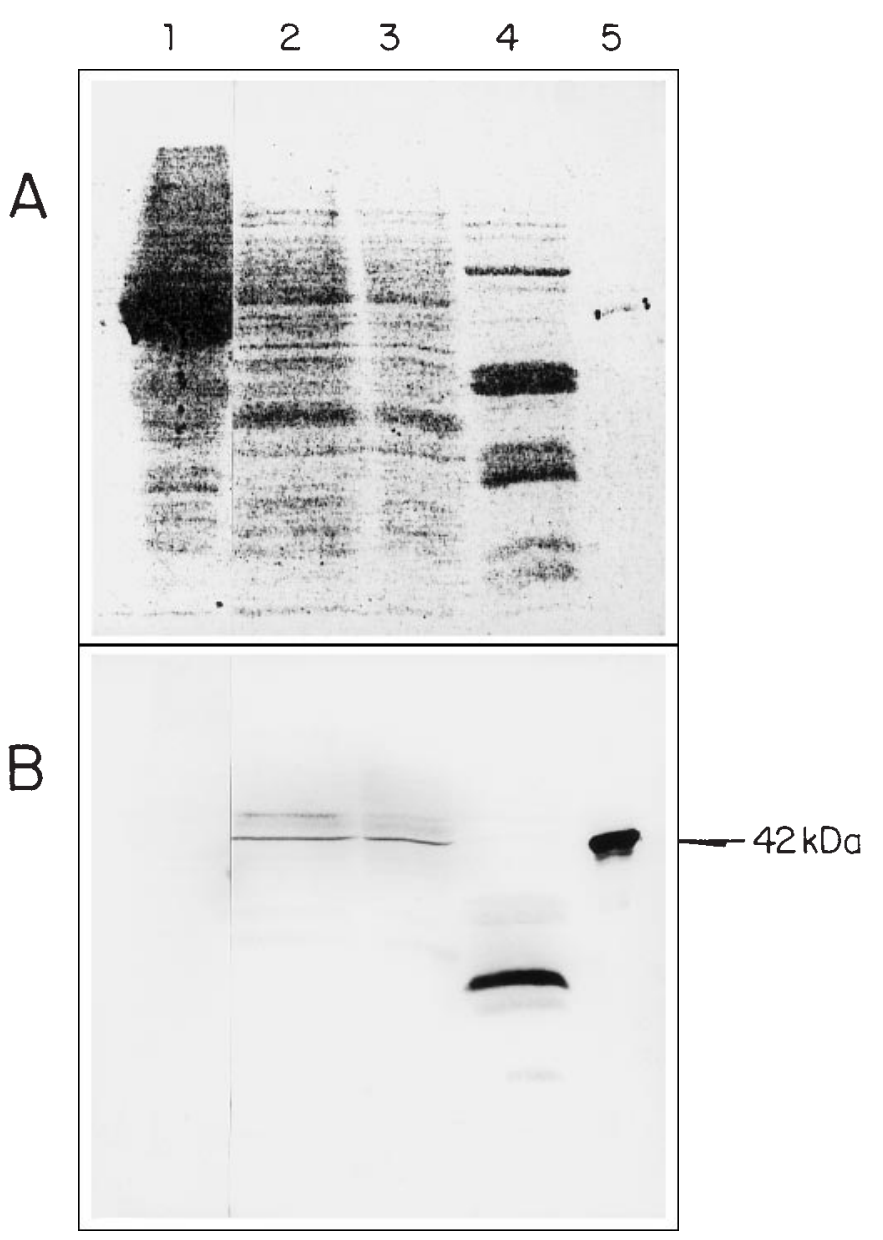

Fig. 1A,B. Immunodetection of actin in seeds from several species by western immunoblotting with anti-(calf thymus actin) polyclonal antibodies. The corresponding seeds were powdered and extracted with SDS-PAGE sample buffer, the supernatants from maize, oats and rice were loaded in equivalent amounts in each lane $(\approx 40 \mu \mathrm{g})$, and the common bean extract load was doubled $(\approx 80 \mu \mathrm{g})$ on a $10 \%$ polyacrylamide gel followed by electrotransfer and immunoblotting. The proteins stained with ponceau S (A) show the protein load for each extract. The immunoblot (B) detected the $42-\mathrm{kDa}$ actin band only in the positive chicken-muscle control (lane 5), maize (lane 2) and oat (lane 3) extracts; possible degraded actin polypeptides were detected in rice extracts (lane 4), and no band in P. vulgaris extracts (lane 1)

The actin product shows a substantial increase during imbibition. Western blot analysis and overdeveloping the blot for a longer time than used previously (Fig. 1) for whole seed extracts revealed that, initially, actin was hardly detectable (Fig. 3,0 h) and that its level remained essentially unchanged during the first $24 \mathrm{~h}$ of imbibition (Fig. 3, 0-24 h). A substantial amount of the protein product was only detected after $48 \mathrm{~h}$ and prevailed from then until $72 \mathrm{~h}$ after imbibition (Fig. 3, 48-72 h).

The results confirmed our expectation that the majority of the actin was found in the embryo (Fig. 2B), since it is the seed part that elongates during germination to become a new plant. Therefore, we repeated the timecourse of induction but analyzing only the embryo axis. The analysis was carried out with both a polyclonal (Villanueva et al. 1990), and a monoclonal anti-actin 


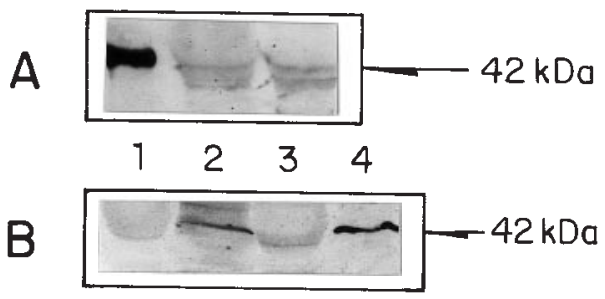

Fig. 2. A Western blot analysis with anti-(calf thymus actin) polyclonal antibodies of whole $P$. vulgaris seeds. The seeds were extracted with $1 \%$ SDS (lane 2) or sample buffer (lane 3) and equivalent amounts of protein were loaded in lanes 2 and $3(\approx 50 \mu \mathrm{g})$. The actin polypeptide was barely detectable even after overdeveloping the blot (lanes 2, 3); however, the chicken-muscle actin control was readily detected (lane 1). B Western blot analysis with anti-(calf thymus actin) polyclonal antibodies of different components of $P$. vulgaris seeds extracted with sample buffer. The seeds were separated into embryos and cotyledons, and extracts from each were made as for the whole seed. Equivalent amounts of protein $(\approx 40 \mu \mathrm{g})$ were loaded in lanes $1-3$. The $42-\mathrm{kDa}$ actin band was not detected in whole seeds (lane 1) or cotyledons (lane 3 ) but it was readily detectable in embryos (lane 2) and the positive chicken-muscle control (lane 4). In both cases (A and $\mathbf{B}$ ), the immunoblot had to be overdeveloped in order to visualize the 42-kDa polypeptide (arrows) in whole-seed and cotyledon extracts

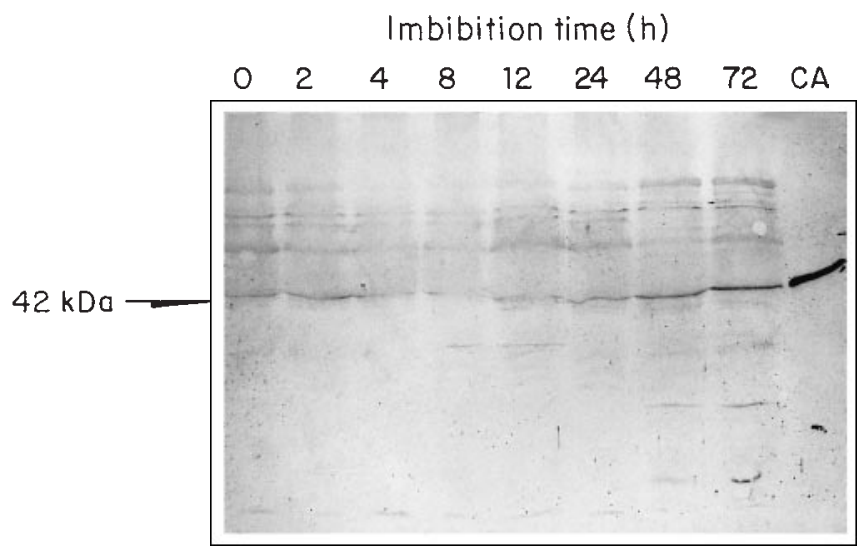

Fig. 3. Time-course analysis of actin during germination of whole seeds of $P$. vulgaris as shown by western immunoblotting using anti(calf thymus actin) polyclonal antibodies. The powdered material from seeds and seedlings at different time points was extracted with SDS-PAGE sample buffer and the supernatants loaded in equivalent amounts $(\approx 50 \mu \mathrm{g})$ directly onto $10 \%$ polyacrylamide gels, followed by electrotransfer and immunoblotting. The blot shows actin in the dry seed at $0,2,4,8,12,24,48$ and $72 \mathrm{~h}$ after imbibition. The positive chicken muscle-actin control $(C A)$ is also shown

(McLean et al. 1990b) antibody and the corresponding blots were analyzed by densitometry (see Materials and methods) to assess the relative increase in actin. In the case of the polyclonal antibody, we observed a certain amount of actin in the dry embryo (Fig. 4, 0 h), which increased about 2-fold after $6 \mathrm{~h}$ of imbibition (Fig. 4, $6 \mathrm{~h})$. This level of actin remained virtually unchanged during the first 6-24 h of imbibition (Fig. 4, 6-24 h). However, at $48 \mathrm{~h}$ after imbibition, about a 5-fold increase in the amount of actin was detected (Fig. 4, $48 \mathrm{~h}$ ) and it remained constant for up to $72 \mathrm{~h}$ (Fig. 4, $72 \mathrm{~h}$ ). The monoclonal antibody yielded similar results

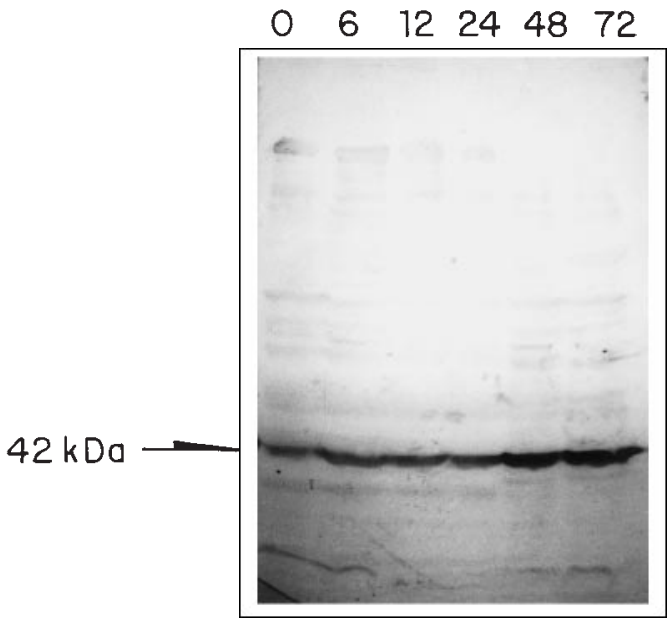

Fig. 4. Time-course analysis of actin during germination of embryo axes of $P$. vulgaris as shown by western immunoblotting using anti(calf thymus actin) polyclonal antibodies. The powdered material from embryo axes at different time points was extracted with sample buffer and the supernatants loaded in equivalent amounts $(\approx 45 \mu \mathrm{g})$ onto $10 \%$ polyacrylamide gels followed by electrotransfer and immunoblotting. The blot shows the presence of actin at $0,6,12$, 24, 48 and $72 \mathrm{~h}$ after imbibition

(data not shown). These data indicate that actin is at low levels in the embryo axis of dry seeds and the polypeptide increases substantially after the first $24 \mathrm{~h}$ of germination. This is the reason for detecting the protein only after $48 \mathrm{~h}$ of germination in whole seeds.

The actin $m R N A$ is induced during germination in seeds of $P$. vulgaris. Initially, when we analyzed $5 \mu \mathrm{g}$ of total mRNA, we were surprised that actin mRNA could not be detected in dry seeds of common bean on northern blots probed with a $P$. vulgaris leaf cDNA (PLACT-6) (Fig. 5A, $0 \mathrm{~h}$ ). Therefore, we carried out an analysis of the actin mRNA using the $P$. vulgaris leaf cDNA $(P L A C T-6)$ in whole seeds at various time points after imbibition. The actin mRNA was not detected during the first $0-12 \mathrm{~h}$ (Fig. 5A, PLACT-6, 0-12 h). The message was barely detectable even after $24 \mathrm{~h}$ of imbibition (Fig. 5A, PLACT-6, $24 \mathrm{~h}$ ); however, its expression increased substantially after $48 \mathrm{~h}$ (Fig. 5A, PLACT-6, $48 \mathrm{~h}$ ). In contrast, the message for a seedspecific gene, LEA-IV showed an initial high expression and then a decrease as the time of imbibition proceeded (Fig. 5A, lea4-25). In addition, analysis of the actin mRNA in embryo axes revealed an increase in the expression similar to that encountered in the whole seeds (Fig. 5B, PLACT-6). In the first hours of imbibition, no message was detected from 0 to $12 \mathrm{~h}$ (Fig. 5B, PLACT$6,0-12 \mathrm{~h}$ ). At $24 \mathrm{~h}$, the hybridization signal was barely detectable (Fig. 5B, PLACT-6, $24 \mathrm{~h}$ ) but at 48 and $72 \mathrm{~h}$, a strong signal was observed indicating a higher level of expression (Fig. 5B, PLACT-6, 48, 72 h). In this tissue, expression of LEA-IV is similar to that observed in whole seeds (Fig. 5B, lea4-25). Finally, to ensure that the difference in detection of the various RNAs was not 


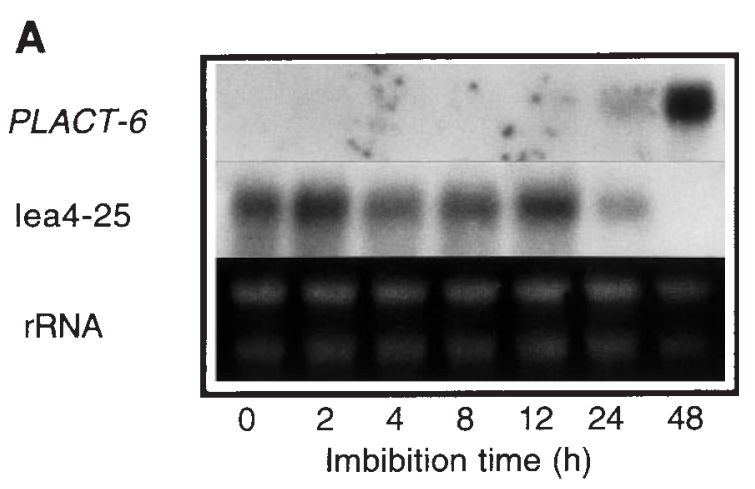

B

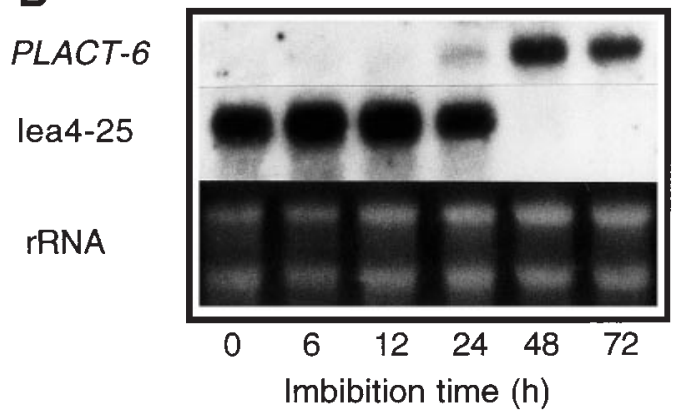

Densitometric Scan

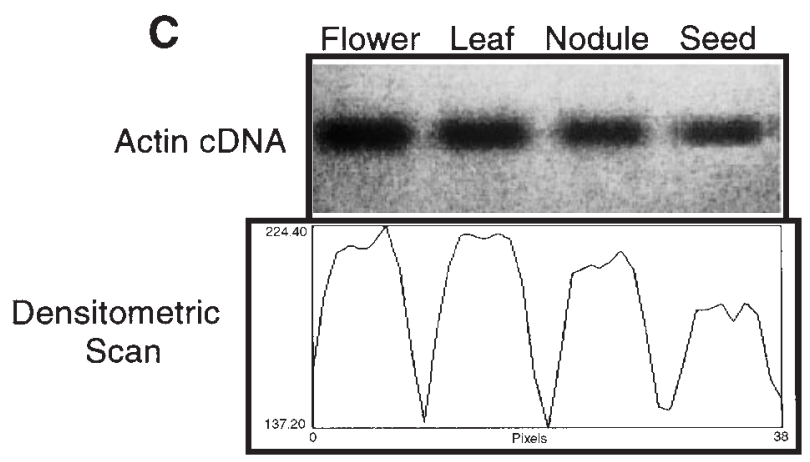

Fig. 5A-C. Northern blot analysis of whole seeds (A) and embryo axes (B), and RT-PCR of flower, leaf, nodule and seed mRNA (C) from $P$. vulgaris in order to detect the actin mRNA. For northern blots, total RNA was prepared from the frozen powdered material by the hot-phenol method, following the procedure of de Vries et al. (1991). Five micrograms of total RNA were run in each lane. Blots were hybridized with $P$. vulgaris LEA class-1 (lea4-25) cDNA (Colmenero-Flores et al. 1997) and actin cDNA from leaves (PLACT-6), at 0, 2, 4, 8, 12, 24 and $48 \mathrm{~h}$ after imbibition for whole seeds (A), and at 0, 6, 12, 24, 48 and $72 \mathrm{~h}$ after imbibition for embryo axes (B). In both whole seeds and embryo axes, equal loading of RNA per lane was checked by ethidium bromide staining of the ribosomal RNAs. The RT-PCR reaction was carried out from 0 to 25 cycles. The actin cDNA from various plant organs and parts was present after 25 cycles; however, the seed cDNA was present in lower amounts as detected by densitometry (C, seed and Densitometric Scan). The y-axis of the graph in $\mathbf{C}$ represents the pixel value

due to differential loading of the gel, the RNA amount loaded in all lanes was standardized using the ribosomal RNAs as a reference (Fig. 5A,B, rRNA).

The dry-seed actin mRNA could not be detected by northern blot analysis; however, we were able to observe the presence of seed actin mRNA by RT-PCR with $5^{\prime}$ and $3^{\prime}$ conserved actin oligonucleotides from the carboxy region, after 25 cycles of amplification (Fig. 5C, seed). The results were consistent with the fact that the actin mRNA in seeds is present in low amounts since the amount detected in this tissue after 25 cycles of amplification was about one-half lower than that of flowers, leaves and nodules (Fig. 5C, densitometric scan). This indicated that the initial amount of seed actin mRNA is not enough to be observed by a regular northern blot analysis under our current detection parameters. These data also suggest that the increase in protein detected in whole seeds during germination is most likely due to an increase in the expression of the actin mRNA that takes place in the embryo.

The induction of the protein is due to an increase in the amount of the two main actin isoforms. To analyze with more detail the characteristics of the actin induction we ran the embryo extracts on 2-D PAGE gels followed by western immunoblotting to detect the isovariants. To ensure that both monoclonal and polyclonal antibodies recognized the same isoforms, the blots initially probed with the monoclonal antibody (Fig. 6A) were washed with SDS-urea to strip off the bound antibodies, reprobed with the immunopurified polyclonal anti-actin antibody and developed by chemiluminescence (Fig. 6B). The results obtained with either antibody were identical (Fig. 6A,B), indicating that both antibodies recognize the same actin isoforms. We observed that in the dry embryo three isoforms of actin already exist, two major isoforms migrate at isoelectric point (pIs) of approx. 5.6 and 5.7, respectively, and a minor isoform at a $\mathrm{pI} \approx 5.8$ (Fig. 6, 0 h). The two major isoforms increase in amount as detected after 24, 48 and $72 \mathrm{~h}$ of imbibition (Fig. 6, 24-72 h). Additionally, a new minor isoform of $\mathrm{pI} \approx 5.5$ appears after $48 \mathrm{~h}$ (Fig. 6, $48 \mathrm{~h}$ ); however, after $72 \mathrm{~h}$ of imbibition this new actin isoform is no longer detected (Fig. 6, $72 \mathrm{~h}$ ). There was some variability in the stretch of the isoelectric focusing gel on which the isovariants migrated; however, the monoclonal antibody cross-reacts with a higher-molecular-weight spot (Fig. 6A, arrow) which has also been observed in soybean (McLean et al. 1990a). This spot was used as an internal reference which allowed us to identify the two major actin isoforms since it was always observed above and between the area where these two major isoforms were focused (Fig. 6A, arrow).

\section{Discussion}

When we tried to detect actin in dry seed extracts of $P$. vulgaris, we were unable to obtain a detectable signal; in contrast, profilin can be readily detected in whole-seed extracts (data not shown). When we compared extracts from different seeds, we observed that the 42-kDa polypeptide corresponding to actin was readily detectable in maize and oats, and possible degradation products from it in rice, but at the same or a higher protein concentration, common-bean actin was still undetectable (Fig. 1). The absence of actin was not 


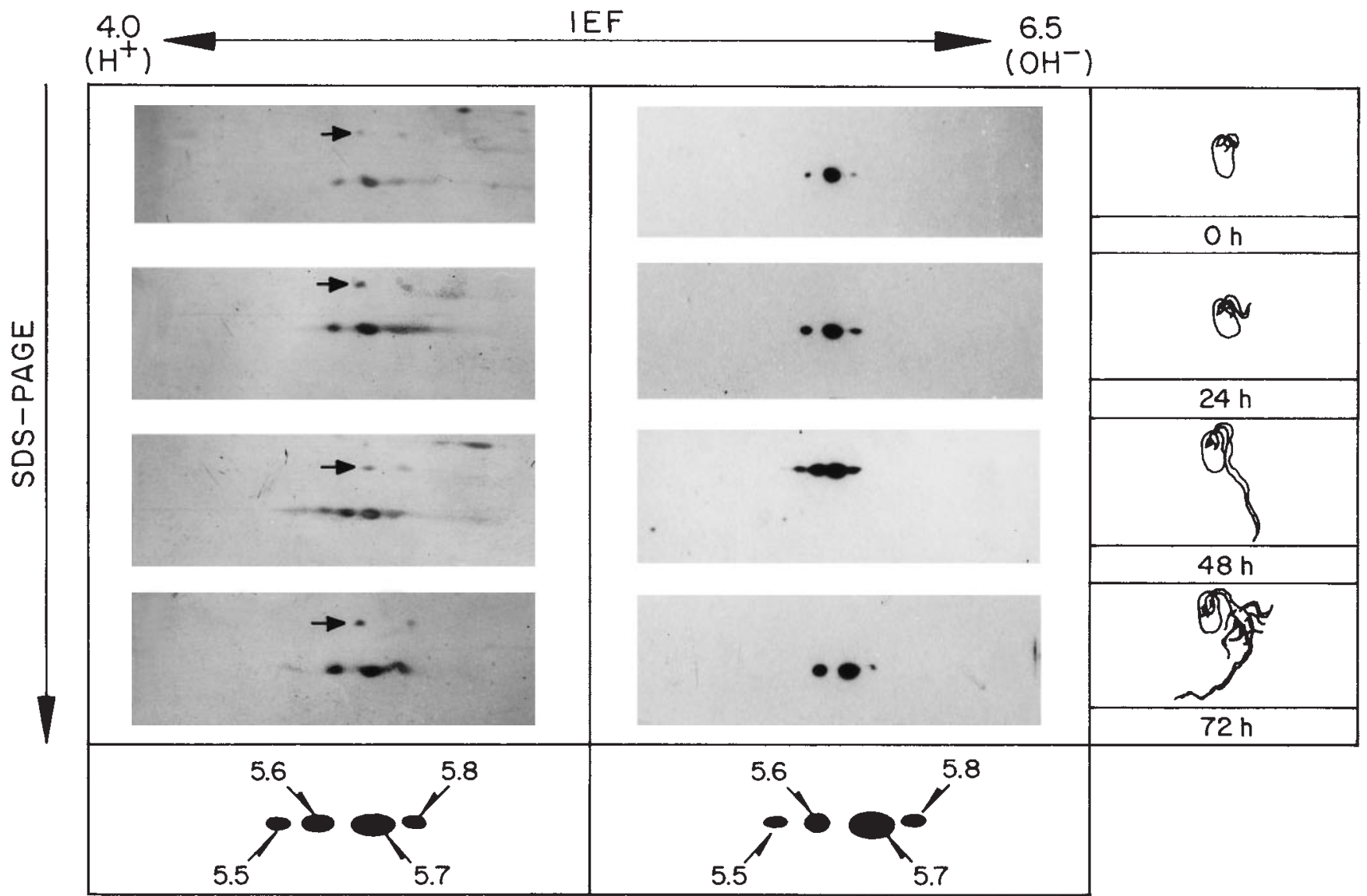

A

Fig. 6A,B. Two-dimensional gel electrophoretic analysis of actin isoform expression at different time points after imbibition of $P$. vulgaris seeds. Embryo axes were excised and extracted in SDS-PAGE sample buffer and analyzed by 2D-PAGE according to O'Farrell (1975). Equal amounts of protein for all time points $(\approx 40 \mu \mathrm{g})$ were loaded in the first dimension. A Immunodetection of the actin isoforms with Amersham N350 monoclonal antibody and alkaline-phosphatase-conjugated secondary antibodies at $0,24,48$ and $72 \mathrm{~h}$ after imbibition. The arrow points toward a cross-reactive protein that was used as a reference point. B The bound antibodies were stripped off the blots and re-probed with immunopurified anti-calf thymus actin polyclonal antibodies followed by peroxidase-labeled secondary antibodies, and developed by chemiluminescence. The pI values of the corresponding isoforms are shown in the bottom panels. The developmental stage of the seedling is schematized along with the time point at the right of the figure

due to degradation during the extraction since commonbean seeds have no detectable proteolytic activity (not shown). Further analysis of separate components of the seed revealed that a $42-\mathrm{kDa}$ polypeptide corresponding to actin was indeed present in the dry seed but it predominated in the embryo (Fig. 2B) and it could be observed in whole seeds only after developing the western blot for a long time (Fig. 3). These data are noteworthy in the context that the embryo is the part of the seed that will become a new plant and it requires the necessary machinery for the dynamic processes that will occur at the onset of germination. The cytoskeleton is certainly an essential component that will be required during this process. Consistent with these data is the fact that profilin is also present predominantly in the embryo from $P$. vulgaris seeds (data not shown).

Actin has been previously used as an internal control for constitutive genes (Cook et al. 1995). In vegetative tissues this may work properly as a control for baseline gene expression but it may ultimately depend on the particular specificity of the probe and the tissue tested. In fact, it was recently reported that an Arabidopsis actin gene, $A C T 7$, has a preferential expression in rapidly growing zones of this plant (McDowell et al. 1996). The finding of extremely low levels of actin in the dry seed of $P$. vulgaris suggested the possibility that, in common bean, there was also a differential actin expression during the germination process. When we performed the analysis of protein expression at different time points of germination, we found that the protein was indeed induced slowly at first $(0-24 \mathrm{~h})$ and then more strongly after $48 \mathrm{~h}$ of imbibition (Fig. 3). We found a 2- to 5-fold increase in the amount of the protein which was consistent with the level of expression of the corresponding mRNA. The times of induction were essentially the same when either the whole seed or the embryo axes alone were analyzed. Although the actin mRNA could not be detected at time $=0$ of imbibition (whole 
dry seed) by northern blot analysis, we were able to amplify actin cDNA from seed mRNA by RT-PCR, indicating that the message is nevertheless present in the dry seed. The amount of the amplified cDNA detected in this plant component after 25 cycles was approximately $50 \%$ less than that obtained from flower, leaf and nodule mRNA (Fig. 5C), which supports the fact that initial actin mRNA in the seed is present in low quantity.

One possibility to account for the increase in the expression of actin was that new genes were being induced or their products modified during the process. Analysis of the extracts at the different time points by 2D-PAGE indicated that: (i) actin is present in the embryo of the common-bean seed as one minor and two major isoforms; (ii) that as many as four isoforms are detected after $48 \mathrm{~h}$ of imbibition but the appearance of the new minor isoform seems to be transient; and (iii) the increase in the protein product is mostly due to the increase in the quantity of the two main isoforms initially present in the embryo instead of a shift of isoform expression (Fig. 6). It is also noteworthy that the pIs determined for the actin isoforms in the common bean correspond closely to actin isoforms already reported from soybean (McLean et al. 1990b), which would suggest an equivalent expression in both species during the vegetative stage. We have determined that there are five to six actin genes present in the $P$. vulgaris genome (data not shown) so that each one of the proteins detected could account for one particular gene product. There is a possibility though, that they could arise from a few genes and be modified post-translationally. Such post-translational modifications of actin have been documented in the literature previously (Aktories and Wegner 1992). As was expected from the protein data, the lack of detection of the actin mRNA in the primary stages of germination did not mean that it was not present; indeed, RT-PCR analysis using universal and plant-actin-specific oligonucleotides showed that the seed actin mRNA could be amplified to a detectable level (Fig. 5C, seed).

It is clear that actin is not always a constitutively expressed protein as previously thought. High levels of regulation of actin have now been encountered at the transcriptional (Lloyd and Gunning 1993), translational and post-translational (Aktories and Wegner 1992; Howard et al. 1993) levels. It remains to be determined if one or both of the main actin isoforms that increase during germination in common bean are products arising from a homolog of the ACT7 gene (McDowell et al. 1996). This gene was observed to be highly expressed in rapidly expanding tissues of Arabidopsis, including a strong expression in the seedlings immediately after imbibition. Its expression was also observed to increase upon treatment with external stimuli such as auxin, light and wounding (McDowell et al. 1996). Thus, it would not be surprising to find an analogy in the expression of actin genes during the germinative process of common bean.

Finally, we could envision two possible scenarios for the existence of such a small amount of actin in cotyledons and the majority of the actin in the embryo.
One would be that actin is not required for the initial triggering of germination. The other possibility is that the basal-level amount of actin present in the seed is enough to allow the embryo to carry out the baseline functions required to trigger the germination event. Once this has occurred, actin expression is induced to continue with the development of the new plant.

This work was supported in part by grants 4733-N and 00131-PN from CONACyT (Consejo Nacional de Ciencia y Tecnología), and grants IN-201696 and IN-202895 from DGAPA-UNAM. We also acknowledge Sergio Trujillo, Alejo Pichardo and Pedro Saucedo for their photographic and art work.

\section{References}

Aktories K, Wegner A (1992) Mechanisms of the cytopathic action of actin-ADP-ribosylating toxins. Mol Microbiol 6: 2905-2908

Andersland JM, Jagendorf AT, Parthasarathy MV (1992) The isolation of actin from pea roots by DNase I affinity chromatography. Plant Physiol 100: 1716-1723

Beven A, Guan Y, Peart J, Cooper C, Shaw P (1991) Monoclonal antibodies to plant nuclear matrix reveal intermediate filament-related components within the nucleus. J Cell Sci 98: 293-302

Bradford MM (1976) A rapid and sensitive method for the quantitation of microgram quantities of protein utilizing the principle of protein-dye binding. Anal Biochem 22: 248-254

Cárdenas L, Vidali L, Domínguez J, Pérez H, Sánchez F, Hepler PK, Quinto C (1998) Rearrangement of actin microfilaments in plant root hairs responding to Rhizobium etli nodulation signals. Plant Physiol 116: 871-877

Church GM, Gilbert W (1984) Genomic sequencing. Proc Natl Acad Sci USA 81: 1991-1995

Colmenero-Flores JM, Campos F, Garcíarrubio A, Covarrubias A (1997) Characterization of genes responsive to water deficit in Phaseolus vulgaris. Characterization of a novel LEA-like protein. Plant Mol Biol 35: 393-405

Cook D, Dreyer D, Bonnet D, Howell M, Nony E, Vandenbosch K (1995) Transient induction of a peroxidase gene in Medicago truncatula precedes infection by Rhizobium meliloti. Plant Cell 6: $43-55$

de Vries S, Hoge H, Bisseling T (1991) Isolation of total and polysomal RNA from plant tissues. In: Gelvin SB, Schilperoort RA, Verma DPS (eds) Plant molecular biology manual, vol 86. Kluwer Academic Publishers, Dordrecht, Netherlands, pp 1-13

Haarer BK, Lillie SH, Adams AEM, Magdolen V, Bandlow W, Brown SS (1990) Purification of profilin from Saccharomyces cerevisiae and analysis of profilin-deficient cells. J Cell Biol 110: $105-114$

Howard PK, Sefton BM, Firtel RA (1993) Tyrosine phosphorylation of actin in Dictyostelium associated with cell-shape changes. Science 259: 241-244

Jungbluth A, Eckerskorn C, Gerisch G, Lottspeich F, Stocker S, Schweiger A (1995) Stress-induced tyrosine phosphorylation of actin in Dictyostelium cells and localization of the phosphorylation site to tyrosine-53 adjacent to the DNase I binding loop. FEBS Lett 375: 87-90

Laemmli UK (1970) Cleavage of structural proteins during the assembly of the head of bacteriophage T4. Nature 227: 680-685

Liu X, Yen L-F (1992) Purification and characterization of actin from maize pollen. Plant Physiol 99: 1151-1155

Lloyd C, Gunning P (1993) Noncoding regions of the G-actin gene influence the impact of the gene on myoblast morphology. J Cell Biol 121: 73-82

Lloyd CW, Slabas AR, Powell AJ, MacDonald G, Badley RA (1979) Cytoplasmic microtubules of higher plants visualised with anti-tubulin antibodies. Nature 279: 239-241 
McCurdy DW, Williamson RE (1991) Actin and actin-associated proteins. In: Lloyd CW (ed) The cytoskeletal basis of plant growth and form. Academic Press, New York, pp 314

McDowell JM, An Y-Q, Huang S, McKinney EC, Meagher RB (1996) The Arabidopsis ACT7 gene in expressed in rapidly developing tissues and responds to several external stimuli. Plant Physiol 111: 699-711

McLean BG, Eubanks S, Meagher RB (1990a) Tissue-specific expression of divergent actins in soybean root. Plant Cell 2: 335-344

McLean BG, Huang S, McKinney EC, Meagher RB (1990b) Plants contain highly divergent actin isovariants. Cell Motil Cytoskel 17: 276-290

O'Farrell PM (1975) High resolution two dimensional gel electrophoresis. J Biol Chem 250: 4007-4021

Pérez HE, Sánchez N, Vidali L, Hernández JM, Lara M, Sánchez F (1994) Actin isoforms in non-infected roots and symbiotic root nodules of Phaseolus vulgaris L. Planta 193: 51-56

Pollard TD, Cooper JA (1986) Actin and actin-binding proteins. A critical evaluation of mechanisms and functions. Annu Rev Biochem 55: 987-1035

Ren H, Gibbon BC, Ashworth SL, Sherman DM, Yuan M, Staiger CJ (1997) Actin purified from maize pollen functions in living plant cells. Plant Cell 9: 1445-1457
Sambrook J, Fritsch EF, Maniatis T (1989) Molecular cloning. A laboratory manual, 2nd edn. Cold Spring Harbor Laboratory Press, Cold Spring Harbor, NY, USA

Schmit A-C, Lambert A-M (1990) Microinjected fluorescent phalloidin in vivo reveals the F-actin dynamics and assembly in higher plant mitotic cells. Plant Cell 2: 129-138

Sheterline P, Sparrow JC (1994) Actin. Protein Profile 1: 1-121

Sinclair J, Rickwood D (1981) Two-dimensional gel electrophoresis. In: Hames BD, Rickwood D (eds) Gel electrophoresis of proteins. IRL Press, Washington DC, pp 189-218

Staiger CJ, Yuang M, Valenta R, Shaw PJ, Warn RM, Lloyd CW (1994) Microinjected profilin affects cytoplasmic streaming in plant cells by rapidly depolymerizing actin microfilaments. Curr Biol 4: 215-219

Towbin J, Staehelin T, Gordon J (1979) Electrophoretic transfer of proteins from polyacrylamide gels to nitrocellulose sheets. Proc Natl Acad Sci USA 76: 4350-4354

Vahey M, Scordilis SP (1980) Contractile proteins from tomato. Can J Bot 58: 797-801

Villanueva MA, Ho S-Ch, Wang JL (1990) Isolation and characterization of one isoform of actin from cultured soybean cells. Arch Biochem Biophys 277: 35-41

Yadav NS, Filner P (1983) Tubulin from cultured tobacco cells: isolation and identification based on similarities to brain tubulin. Planta 157: 46-52 